\title{
Wyznaczanie dopuszczalnej wielkości szczeliny w złączu spawanym ze względu na możliwość jego pękania
}

\author{
Calculating the permissible size of the fissure \\ in welded joint because of the possibility of his cracking
}

\section{Streszczenie}

Praca przedstawia podstawowe zależności i wzory stosowane do wyznaczania dopuszczalnej wielkości szczeliny w złączu spawanym ze względu na możliwość jego pęknięcia. Wyznaczono dopuszczalne wielkości szczeliny dla dwóch typów stalowych złączy spawanych z uwzględnieniem założonego modelu rozkładu naprężeń własnych. Obliczenia wykonano na podstawie krytycznych właściwości materiałowych złącza, stosowanych w mechanice pękania, tj: odporności na pękanie i krytycznej wartości rozwarcia czoła pęknięcia. Właściwości te wyznaczono na podstawie wyników badań udarności złączy spawanych.

Słowa kluczowe: złącza spawane, kruche pękanie, niezgodności złączy spawanych

\section{Abstract}

The work presents basic dependences and formulas applied to calculating the permissible size of the fissure in welded joint because of the possibility of his cracking. The permissible sizes of the fissure were evaluated for two types of steel welded joints with the regard put model of the residual stress distribution. The calculations were made on the basis of the critical material proprieties of welded joint, applied in the mechanics of cracking, i.e.: fracture toughness and the critical value of crack tip opening displacement. These proprieties were assigned on basis of the test results of impact resistance of welded joints.

Keywords: welded joints, fragile cracking, welded joints incompatibilities

\section{Wstęp}

Wyznaczanie krytycznej lub dopuszczalnej wielkości szczelin w złączach spawanych ze względu na możliwość ich nagłego - kruchego pękania oparte jest, zgodnie z zasadami liniowo-sprężystej mechaniki pękania (LSMP), na wartości współczynnika intensywności naprężenia $K_{\text {I }}$ na czole szczeliny. Kruche - nagłe pęknięcie elementu (złacza) wystąpi gdy współczynnik $K_{\text {। }}$ osiągnie wartość krytyczną $K_{\mathrm{lc}}\left(K_{\mathrm{l}}=K_{\mathrm{lc}}\right)[1,2]$. Ten rodzaj pęknięcia, charakterystyczny dla materiałów kruchych, występuje również w stalach w płaskim stanie odkształcenia - tj. zwykle przy niskim poziomie naprężenia nominalnego względem granicy plastyczności: $S_{r}=\sigma / R_{e}\left(S_{r} \leq 0,5\right) \mathrm{w}$ elementach grubych, gdzie strefa plastyczna na czole karbu w postaci szczeliny istniejącej w elemencie jest bardzo mała i z tego względu można ją pominąć [2:4]. Kryterium LSMP można też stosować przy wyższym poziomie naprężenia, tzn. $\left(05<\mathrm{S}_{\mathrm{r}} \leq 0,8\right)$. Wtedy operuje się efektywnym wymiarem szczeliny - aef, tj. sumą jej wymiaru rzeczywistego a i zasięgu strefy plastycznej na czole szczeliny $-r_{p}\left(a_{e f}=a+r_{p}\right)[2,3]$.

Karby czyli niezgodności spawalnicze występujące w złączach spawanych, widoczne na przełomach próbek łamanych udarowo [5], można wykrywać i określać ich wymiary za pomocą badań nieniszczących, np. badań ultradźwiękowych lub radiograficznych.

Wartość współczynnika intensywności naprężenia w złączu spawanym wynika zarówno z naprężeń: nominalnych pochodzących od obciążeń zewnętrznych jak i z naprężeń własnych. Wartość i rozkład naprężeń własnych określa się za pomocą różnych modeli obliczeniowych [2] albo za pomocą analiz numerycznych, przeprowadzanych zwykle metodą elementów skończonych, jak opisano to np. dla złącza krzyżowego w pracy [6].

W przypadku elementów o małej grubości przy wyższym poziomie naprężenia $\left(S_{r}>0,5\right)$ na czole szczeliny pojawia się większa strefa odkształcenia plastycznego, co powoduje wystąpienie quasi-kruchego stanu materiału. O możliwości pękania w takim stanie materiału decyduje wielkość rozwarcia czoła szczeliny $\delta_{a}=2 v_{a}[2 \div 4]$. Wielkość ta po osiągnięciu krytycznej wartości $\delta_{c}\left(\delta_{a}=\delta_{c}\right)$ powoduje quasi-kruche pękanie materiału, zgodnie z założeniami sprężysto-plastycznej mechaniki pękania (SPMP) $[1 \div 4]$. W niskich temperaturach pracy, zwykle w temperaturach rzędu $-20^{\circ} \mathrm{C}$ i niższych, znacznie wzrasta kruchość stali, co pozwala na stosowanie przy $\left(0,5<\mathrm{S}_{\mathrm{r}} \leq 0,8\right)$ LSMP zamiast SPMP.

Dr hab. inż. Krzysztof Werner, prof. PCz; dr inż. Kwiryn Wojsyk, adiunkt PCz - Politechnika Częstochowska. 
Istnienie szczelin w elementach konstrukcyjnych nawet o małych wymiarach (znacznie mniejszych niż wymiary krytyczne) może powodowć wzrost pęknięć pod działaniem obciążeń zmiennych, tj. rozwój pęknięć zmęczeniowych. Złącza spawane są bardzo wrażliwe na działanie obciążeń zmiennych. Dlatego istotne znaczenie mają badania rozwoju pęknięć zmęczeniowych w złączach $[7,8]$ bo umożliwiają określenie trwałości zmęczeniowej złączy.

W literaturze można spotkać prace omawiające metodykę obliczeń wytrzymałościowych złączy spawanych dla obciążeń statycznych i zmęczeniowych wg Eurokodu $3[9,10]$. Jednak znajomość tej tematyki jest wśród kadry inżynierskiej spawalników słaba. Dlatego w tej pracy przedstawiono metodykę i wyniki obliczeń dopuszczalnej długości pęknięć wskrośnych wzdłużnych (równoległych do osi spoiny) w różnych strefach złącza spawanego z uwzględnieniem naprężeń własnych spawalniczych. Temat pracy jest kontynuacją i uogólnieniem zagadnienia związanego z oceną zagrożenia pękaniem złączy spawanych przedstawionego przez autorów tej publikacji w pracy [11].

\section{Wyznaczanie dopuszczalnej wielkości szczeliny w złączu spawanym}

Dopuszczalną wielkość wzdłużnej szczeliny wskrośnej wyznaczono dla doczołowych złączy spawanych w pozycji PF metodą 135 MAG. Złącza z blachy o grubości $\mathrm{g}=12 \mathrm{~mm}$ wykonano ze stali o podwyższonej wytrzymałości S355J2+N w stanie po normalizacji ze spoiną typu "V" $\mathrm{i}$ „1/2 V" [12]. Granica plastyczności blachy stalowej wynosiła $R_{e}=384 \mathrm{MPa}$, a wytrzymałość na rozciąganie $R_{m}=574$ MPa. Odpowiednie właściwości drutu spawalniczego G3Si1 o średnicy d=1,2 mm wynosiły: $R_{e}=450 \mathrm{MPa}$ i $R_{m}=545 \mathrm{MPa}$.

Wartości i rozkład naprężeń własnych w spoinie i w strefie wpływu ciepła (SWC) złącza spawanego oszacowano na podstawie modelu podanego w pracy [2] zgodnie $z$ europejską procedurą FITNET. Według tego modelu własne naprężenia poprzeczne na powierzchni złącza $\sigma_{\mathrm{rt}} \mathrm{W}$ spoinie są równe granicy plastyczności $R_{e}$ materiału rodzimego, a w SWC i materiale rodzimym maleją liniowo do zera na odcinku równym podwójnej grubości blachy. Na rysunku 1 przedstawiono schemat rozkładu własnych naprężeń
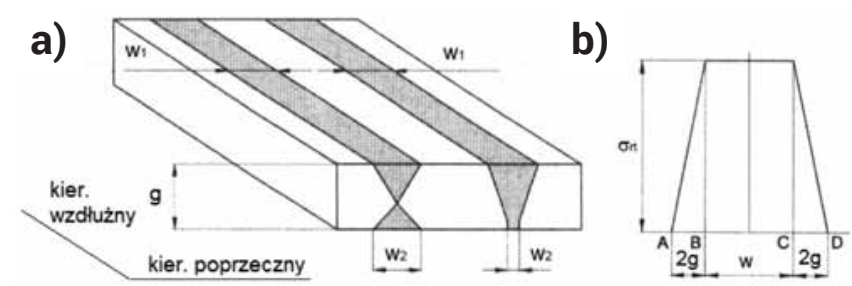

c)

d)
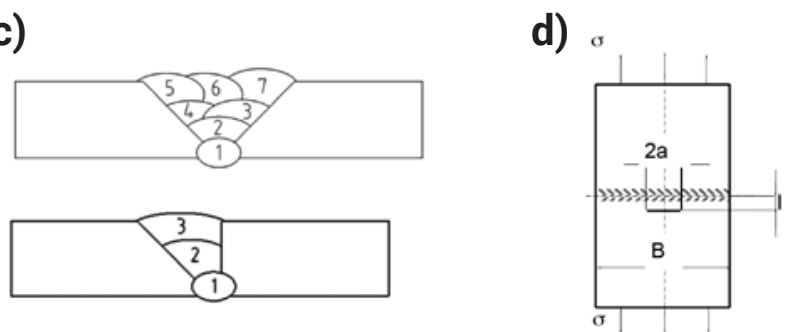

Rys. 1. Schemat złącza spawanego - a) i model rozkładu naprężeń własnych na powierzchniach złącza (w=w1 - lico; w=w2 - grań) - b) oraz schematy ściegów w spoinie typu: V i 1/2 V - c) i złącza z usytuowaniem szczeliny wskrośnej - d)

Fig. 1. The scheme of welding joint $-a)$ and model of residual stress distribution on surface of joint ( $w=w 1-$ face; $w=w 2-$ edge $)-b$ ) as well as schemes welding sequences in the joint of the type: $V$ and $1 / 2$ $\mathrm{V}-\mathrm{c}$ ) and welded joint with location of throughout fissure $-\mathrm{d}$ ) poprzecznych na powierzchni złącza oraz badane typy złączy i schemat złącza ze szczeliną wskrośną o łącznej długości 2a.

Zgodnie z analizą wyników badań zawartych w pracy [12] wartości krytyczne: odporności na pękanie $\mathrm{K}_{\mathrm{lc}}$, i rozwarcia pęknięcia $\delta_{c}$, wyznaczono na podstawie pracy $K_{v}$ udarowego łamania próbek dla każdej strefy złącza w niskich temperaturach wg. zależności $[2,4,11]$ :

$$
\begin{aligned}
& \delta_{\mathrm{c}}=0,0024 \cdot(\mathrm{KV}) \\
& \mathrm{K}_{\mathrm{Ic}}=\sqrt{\mathrm{Re} \cdot \delta_{\mathrm{c}} \cdot \mathrm{E}}
\end{aligned}
$$

Przykładowe wyniki badań KV [J] oraz obliczeń wartości krytycznych $\delta_{\mathrm{c}} \mathrm{i} \mathrm{K}_{\mathrm{lc}}$ dla każdej strefy złącza podano $\mathrm{w}$ tabeli I w pracy [11].

Najprostszym sposobem oceny długości graniczneij $a_{g}$ szczeliny wskrośnej ze względu na jej stabilność, czyli nie rozwijanie się pęknięcia pod wpływem naprężenia rozciągającego - prostopadłego do niej, może być zastosowanie kryterium wynikającego z LSMP [4] przy bardzo wysokim poziomie naprężenia równym granicy plastyczności $\left(\sigma=R_{e}\right)$ :

$$
a_{g} \leq \frac{1}{\pi}\left(\frac{K_{\mathrm{lc}}}{R_{e}}\right)^{2}
$$

Zależność tą można stosować tylko dla elementów o dużej szerokości B, tj. ich wymiarze w kierunku wzrostu długości szczeliny. Zastosowanie tej zależności dla złączy spawanych może jednak dać długości $a_{\mathrm{g}}$ zawyżone w stosunku do innych kryteriów (zwłaszcza w spoinie) ponieważ nie uwzględnia się w niej własnych naprężeń spawalniczych. Podobnie zależność wyznaczona doświadczalnie, zamieszczona w pracy [4], stosowana do określania dopuszczalnej długości $a_{d}$ szczeliny wskrośnej w złączu o szerokości $B$ [mm] przy współcz. bezpieczeństwa $b=2$ na podstawie zasadniczych danych materiałowych i wartości KCV [J/cm²], nie odzwierciedla wpływu poziomu naprężenia na obliczaną wartość $\mathrm{a}_{\mathrm{d}}$ :

$$
\begin{aligned}
& \left.a_{d}=0,5 \cdot\left(p-\sqrt{p^{2}-5 B \cdot(K C V) \cdot\left(1-R_{e} / R_{m}\right.}\right)\right), m m \\
& \text { gdzie: } \\
& p=B+1,25 \cdot(K C V)
\end{aligned}
$$

Wyniki obliczeń długości szczeliny $\mathrm{a}_{\mathrm{g}} \mathrm{i} \mathrm{a}_{\mathrm{d}}$ dla złączy spawanych uzyskane według tych zależności mają charakter orientacyjny [11].

Dopuszczalną długość $a=a_{d}$ centralnej szczeliny wskrośnej o łącznej długości $2 \mathrm{a}_{\mathrm{d}} \mathrm{w}$ złączu o szerokości B wyznaczono dla założonych wartości stosunku B/a (we współczynniku korekcyjnym Y) i współczynnika bezpieczeństwa $b=2$. Obliczenia wykonano $w$ oparciu o prostą wersję kryterium LSMP wg pierwszego poziomu oceny obowiązującego dla $S_{\mathrm{rf}}=\sigma / \sigma_{\mathrm{f}} \leq 0,8$, w którym naprężenie końcowe $\sigma_{\mathrm{f}}$ jest określone jako: $\sigma_{f}=0,5\left(R_{e}+R_{m}\right) \leq 1,2 R_{e}[4]$.

$$
K_{I} / K_{I c}=1 / \sqrt{2}
$$

$$
\begin{aligned}
& \text { gdzie: } \\
& K_{I}=\sigma \sqrt{\pi \cdot a} \cdot Y \quad Y=\sqrt{\frac{B}{\pi \cdot a} \operatorname{tg} \frac{\pi \cdot a}{B}}
\end{aligned}
$$

stąd:

$$
a_{d}=\frac{K_{I c}^{2}}{(\sigma \cdot Y)^{2} \cdot \pi}
$$


Ponadto zgodnie z innym kryterum LSMP [8] wyznaczono też równoważną długość centralnej szczeliny wskrośnej $\mathrm{a}_{\mathrm{m}}$, na postawie której można także określić wymiary szczeliny powierzchniowej odkrytej lub wewnętrznej ukrytej $[4,11]$ :

$$
a_{m}=C\left(K_{i c} / R_{e}\right)^{2}
$$

gdzie:

$$
C=\frac{1}{2 \pi\left[\left(\sigma / R_{e}\right)-0,25\right]} \text { dla } \sigma / R_{e} \geq 0,5
$$

Obliczenia wg wzorów (6) i (7) przeprowadzono dla obciążenia rzeczywistego w każdej strefie złącza, uwzględniając oprócz naprężenia nominalnego rozciągającego na poziomie $S_{r}=0,5$ oraz $S_{r}=0,8$ także naprężenia własne $w$ spoinie, a poza nią - średnie naprężenie własne $z$ obu powierzchni złącza. W obliczeniach uwzględniono różne wartości granicy plastyczności $R_{e}$ materiału rodzimego i spoiny, a w SWC zastosowano do obliczeń liniową zmianę $R_{e}$.

\section{Wyznaczone dopuszczalne długości szczelin wskrośnych w rozpatrywanych złączach}

Wyniki obliczonych dopuszczalnych i równoważnych długości rozpatrywanych typów szczelin dla dwóch temperatur w zależności od ich położenia w złączu spawanym przedstawiono na rysunkach $2 \div 6$.

Wyznaczone w różnej odległości od osi spoiny, tj. w różnych strefach złącza typu $V$, długości graniczne $a_{g}$ szczeliny wg wzoru (3) przy niskim poziomie naprężenia nominalnego $S_{r}=0,5$ (rys. 2) były bardzo wysokie. Podobnie duże były długości dopuszczalne $a_{d}$ tego pęknięcia wyznaczone ze wzoru (4) przy dużej szerokości B złącza typu V. Wraz ze zmniejszaniem szerokości B wartości ad malały. Otrzymane wyniki wg wzorów (3 i 4) korespondują z rezultatami opublikowanymi w pracy [11] (rys. 4).

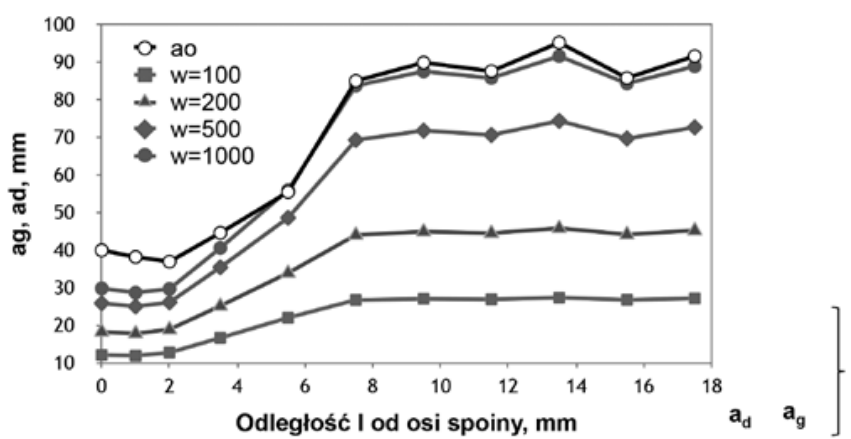

Rys. 2. Długość szczeliny: graniczna $a_{g}$ (wzór 3 ) oraz dopuszczalna $\mathrm{a}_{\mathrm{d}}$ (wzór 4). Złącze spawane typu $\mathrm{V} ; \mathrm{t}=-25^{\circ} \mathrm{C} ; \mathrm{Sr}=0,5$

Fig. 2. The length of fissure: limitary $a_{g}$ (formula 3 ) and permissible $\mathrm{a}_{\mathrm{d}}$ (formula 4). Welded joint of type $\mathrm{V} ; \mathrm{t}=-25^{\circ} \mathrm{C} ; \mathrm{Sr}=0,5$

Na uwagę zasługuje zbieżność wyników dopuszczalnej długości szczeliny $a_{d}$ otrzymanych ze wzoru (4) dla złącza o dużej szrokości $(B=1000 \mathrm{~mm})$ z wynikami $a_{\mathrm{g}}$ wyznaczonymi ze wzoru (3), zwłaszcza dla szczeliny położonej w odległości l > $4 \mathrm{~mm}$ od osi spoiny.

Wyniki obliczeń dopuszczalnej długości $a_{d}$ szczeliny wskrośnej wg wzoru (6) dla złącza typu V w temperaturze $\mathrm{t}=-25^{\circ} \mathrm{C}$ przy niskim poziomie naprężenia nominalnego $\left(\mathrm{S}_{\mathrm{r}}=0,5\right)$ z uwzględnieniem naprężeń własnych, zgodnie z przyjętym rozkładem modelowym, były niższe niż odpowiednie długości równoważne $a_{m}$ wyznaczone wg wzoru
(7) dla tej szczeliny w tych samych warunkach (rys. 3). Zapewne wynika to z przyjętej wartości współczynnika bezpieczeństwa b=2 we wzorze (6). Ze wzrostem odległości l, określającej położenie szczeliny od osi spoiny, wzrasta zarówno długość $a_{d}$, jak i $a_{m}$. Natomiast w obszarze spoiny ( $I=0-3,5$ $\mathrm{mm}$ ) wartości te są prawie stałe.

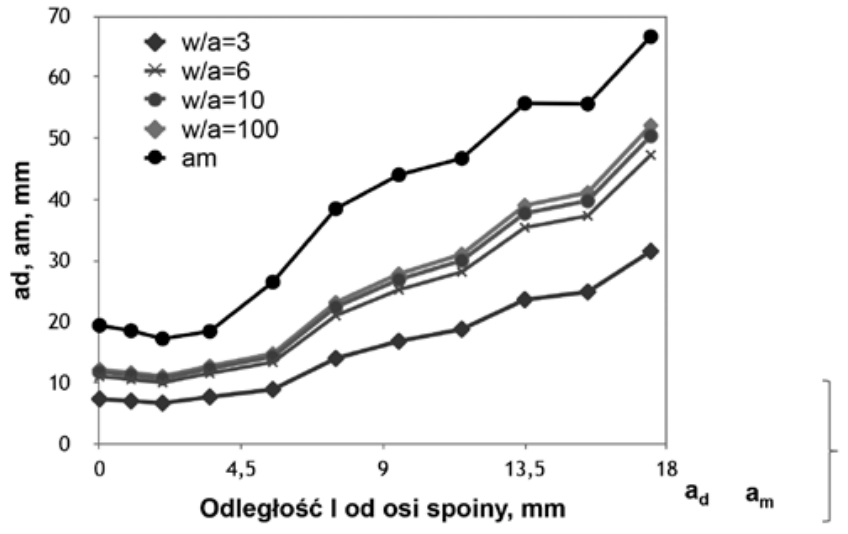

Rys. 3. Długość szczeliny: dopuszczalna $a_{d}$ (wzór 6) oraz równoważna $\mathrm{a}_{\mathrm{m}}$ (wzór 7). Złącze spawane typu $\mathrm{V} ; \mathrm{t}=-25^{\circ} \mathrm{C} ; \mathrm{S}_{\mathrm{r}}=0,5$

Fig. 3. The length of fissure: permissible $a_{d}$ (formula 6 ) and equivalent $\mathrm{a}_{\mathrm{m}}$ (formula 7 ). Welded joint of type $\mathrm{V} ; \mathrm{t}=-25^{\circ} \mathrm{C} ; \mathrm{S}_{\mathrm{r}}=0,5$

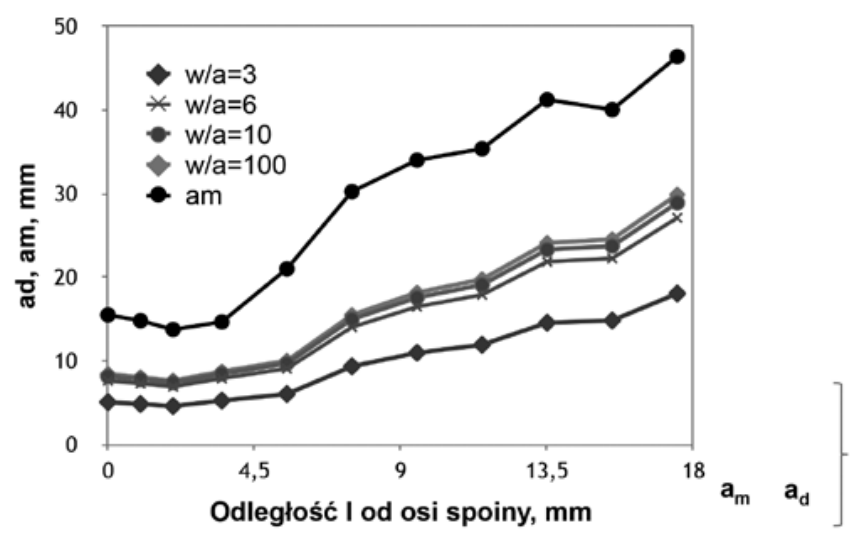

Rys. 4. Długość szczeliny: dopuszczalna $a_{d}$ (wzór 6 ) oraz równoważna $a_{m}$ (wzór 7). Złącze spawane typu $V ; t=-25^{\circ} \mathrm{C} ; S_{r}=0,8$

Fig. 4. The length of fissure: permissible $a_{d}$ (formula 6 ) and equivalent $\mathrm{a}_{\mathrm{m}}$ (formula 7 ). Welded joint of type $\mathrm{V} ; \mathrm{t}=-25^{\circ} \mathrm{C} ; \mathrm{S}_{\mathrm{r}}=0,8$

Podobny charakter zmiany wartości wyznaczanych długości szczeliny wskrośnej w złączu typu $V$ jak dla poziomu $\mathrm{S}_{\mathrm{r}}=0,5$ stwierdza się także przy wyższym poziomie obciążenia $S_{r}=0,8$ (rys. 4). Jednak w związku z wyższym poziomem naprężenia od obciążenia zewnętrznego przy $\mathrm{S}_{\mathrm{r}}=0,8$ wyznaczone długości szczeliny są mniejsze.

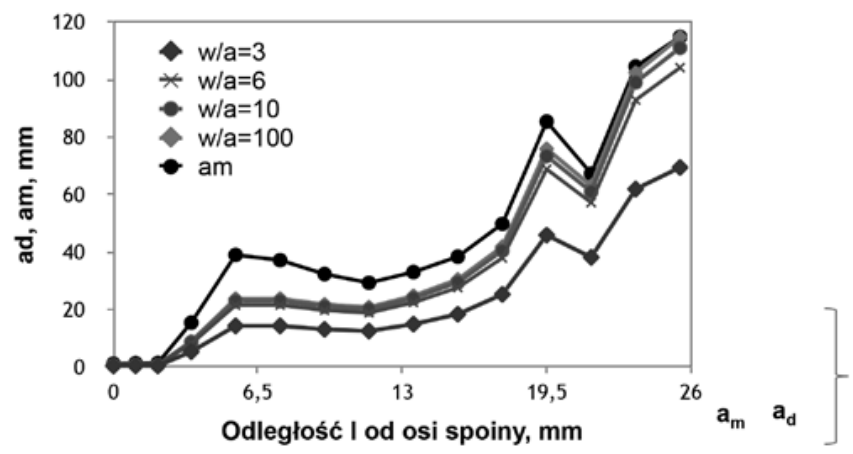

Rys. 5. Długość szczeliny: dopuszczalna $a_{d}$ (wzór 6) oraz równoważna $a_{m}$ (wzór 7). Złącze spawane typu $1 / 2 \mathrm{~V} ; \mathrm{t}=-75^{\circ} \mathrm{C} ; \mathrm{S}_{\mathrm{r}}=0,5$

Fig. 5. The length of fissure: permissible $a_{d}$ (formula 6 ) and equivalent $\mathrm{a}_{\mathrm{m}}$ (formula 7 ). Welded joint of type $1 / 2 \mathrm{~V} ; \mathrm{t}=-75^{\circ} \mathrm{C} ; \mathrm{S}_{\mathrm{r}}=0,5$ 
Wyznaczone długości szczeliny wskrośnej: $a_{d}$ i $a_{m}$ w złączu typu $1 / 2$ V dla znacznie niższej temperatury $\left(t=-75^{\circ} \mathrm{C}\right)$ zilustrowane na rysunku 5 dla $S_{r}=0,5$ wskazują, że w strefie spoiny ( $(=0-2 \mathrm{~mm}$ ) pęknięcie złącza może wystąpić przy bardzo małej długości szczeliny am równej około 1,5 $\mathrm{mm}$. Odpowiadająca tej strefie dopuszczalna długość szczeliny ad wynosiła około $1 \mathrm{~mm}$. Świadczy to o dużej wrażliwości danego gatunku stali w zakresie niskich temperatur pracy. Długości $a_{d}$ i $a_{m}$ szczeliny położonej poza strefą spoiny są znacznie większe i w materiale rodzimym na granicy oddziaływania naprężeń własnych (I > 25,5 mm) przy dużej wartości parametru $\mathrm{B} / \mathrm{a}(\mathrm{B} / \mathrm{a}=100)$ mają wartości zbliżone do siebie - równe około $115 \mathrm{~mm}$.

$\mathrm{Na}$ uwagę zasługuje fakt, że $\mathrm{w}$ odległości I = 2-5 mm od osi spoiny wyznaczone długości szczeliny: dopuszczalna ad i krytyczna am wzrastają liniowo bardzo szybko. Może to wynikać z szybkiego "wchodzenia" szczeliny w obszar SWC W złączu typu $1 / 2 \mathrm{~V}$ po przekroczeniu odległości I = $2 \mathrm{~mm}$. Ma to związek z typem złącza spawanego. Dla złącza typu $1 / 2$ V granica między spoiną a SWC jest prostopadła do powierzchni złącza (jedna z łączonych blach złącza nie jest sfazowana). W przypadku złącza typu $V$ granica ta, z uwagi na kształt brzegu łączonej blachy, przebiega ukośnie dzięki czemu zmiany rozpatrywanych długości szczeliny mają charakter łagodniejszy (rys. 3 i 4). Podobnie w zależności od typu złącza zaznacza się wpływ granicy pomiędzy SWC a materiałem rodzimym złącza. Wpływ ten jest wyraźny dla złącza typu $1 / 2$ V. Po przekroczeniu tej granicy $(I=5,5 \mathrm{~mm})$ dopuszczalna długość szczeliny ad jest prawie stała, a am ulega niewielkiemu zmniejszaniu dla I = 5,5-1 1,5 mm (rys. 5). Natomiast w złączu typu $\vee$ wpływ ten jest bardzo nieznaczny, co widać na rysunku 3 i 4 dla I >7,5 mm.

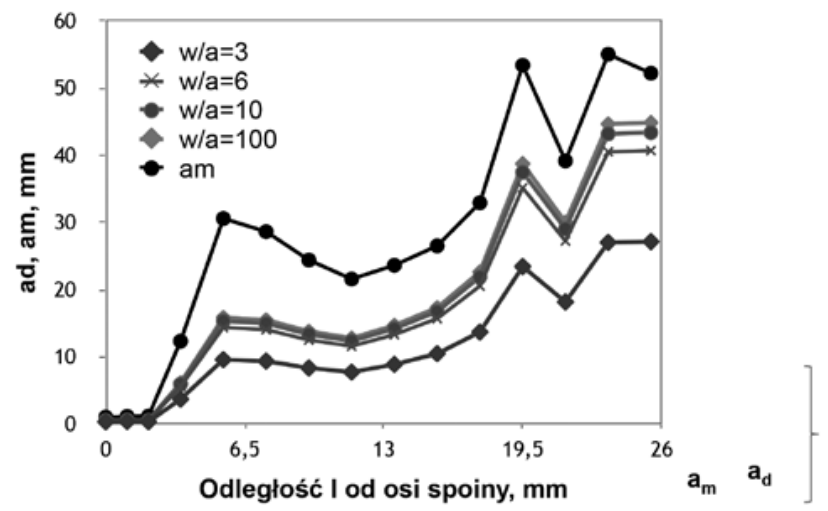

Rys. 6. Długość szczeliny: dopuszczalna $a_{d}$ (wzór 6) oraz równoważna $\mathrm{a}_{\mathrm{m}}$ (wzór 7). Złącze spawane typu $1 / 2 \mathrm{~V} ; \mathrm{t}=-75^{\circ} \mathrm{C} ; \mathrm{S}_{\mathrm{r}}=0,8$

Fig. 6 . The length of fissure: permissible $a_{d}$ (formula 6 ) and equivalent $\mathrm{a}_{\mathrm{m}}$ (formula 7 ). Welded joint of type $1 / 2 \mathrm{~V} ; \mathrm{t}=-75^{\circ} \mathrm{C} ; \mathrm{S}_{\mathrm{r}}=0,8$

\section{Podsumowanie}

Na podstawie przeprowadzonej analizy możliwości wyznaczania dopuszczalnych wielkości wzdłużnej szczeliny wskrośnej w doczołowym złączu spawanym sformułowano następujące spostrzeżenia i wnioski:

Wyznaczone w różnych strefach złącza długości szczeliny, tj długość: graniczna $a_{g}$ wg wzoru (3) i dopuszczalna $a_{d}$ wg wzoru (4) dla złącza o dużej szerokości, były prawie identyczne poza strefą spoiny ale znacząco większe niż wyznaczone z innych zależności zastosowanych w tej pracy. Dlatego wyniki obliczeń długości szczeliny $\mathrm{a}_{\mathrm{g}} \mathrm{i} \mathrm{a}_{\mathrm{d}}$ uzyskiwane z tych wzorów należy traktować jako wartości orientacyjne.

Zastosowanie zależności (6) do wyznaczania dopuszczalnej długości szczeliny wskrośnej, przy naprężeniu rzeczywistym - uwzględniającym naprężenia własne, pozwala na uzyskanie dobrej korelacji z wynikami tzw. długości równoważnej $a_{m}$ wyznaczanej z zależności (7) przy tym naprężeniu. Zależność (7) określa wymiar krytyczny szczeliny w złączu o dużej szerokości B w stosunku do wyznaczonej wartości $\mathrm{a}_{\mathrm{m}}$. Wyraźne zmiany wyznczanych wielkości wg obu formuł występują na granicach stref złącza typu $1 / 2 \vee$ po stronie niesfazowanego brzegu łączonej blachy.

Zależność (6), podobnie jak i zależność (7), może być stosowana do różnych typów złącza doczołoswego w szerokim zakresie temperatury. Wyniki obliczeń dopuszczalnej długości ze wzoru (6) są niższe niż ze wzoru (7), co jest spowodowane zastosowaniem współczynnika bezpieczeństwa $b=2$ we wzorze (6). Należy podkreślić też to, że formuła (6) pozwala na uwzględnienie wpływu szerokości złącza na wyznaczaną wartość dopuszczalnej długości szczeliny.

Wyznaczone niewielkie długości $\mathrm{a}_{\mathrm{d}} \mathrm{i} \mathrm{a}_{\mathrm{m}}$ szczeliny wskrośnej w spoinie dla badanych temperatur $\left(\mathrm{zw} ł a s z c z a t=-75^{\circ} \mathrm{C}\right)$ wskazują na dużą wrażliwość stali S355J2+N na niską temperaturę pracy rzędu od -25 do $-75^{\circ} \mathrm{C}$ ze względu na możliwość pękanie jej połączeń spawanych, a zwłaszcza spoin.

\section{Literatura}

[1] Kocańda S.: Zmęczeniowe pęanie metali, WNT Warszawa 198.

[2] Neimitz A.: Mechanika pękania, PWN Warszawa 1998.

[3] Brózda J.: Wprowadzenie do mechaniki pękania, Instytut Spawalnictwa Gliwice 2008

[4] Rykaluk K.: Pęknięcia w konstrukcjach stalowych, Dolnośląskie Wydawnictwo Edukacyjne Wrocław 2000.

[5] Słania J., Staniszewski K., Hyc K.: Ocena przełomów złączy spawanych po próbie łamania. Przegląd Spawalnictwa 12/2013 s. 142-151.

[6] Stasiuk P., Karolczuk A., Kuczko W.: Rozkład naprężeń w krzyżowym złączu spawanym z uwzględnieniem rzeczywistego kształtu spoiny. Przegląd Spawalnictwa 1/2014 s. 29-33.

[7] Prażmowski M., Rozumek D.: Rozwój pęknięć przy cyklicznym zginaniu w złączu cyrkon-stal powstałych w wyniku zgrzewania wybuchowego. Przegląd Spawalnictwa 4/2014 s. 45-50.

[8] Bański R., Rozumek D.: Rozwój pęknięć zmęczeniowych w bimetalach stal-tytan wykonanych metodą zgrzewania wybuchowego (platerowania). Przegląd Spawalnictwa 4/2012 s. 9.
[9] Wichtowski B.: Obliczenia złączy spawanych poddanych obciążeniom statycznym i zmęczeniowym według Eurokodu 3. Przegląd Spawalnictwa $1 / 2011$ s. 15.

[10] Wichtowski B., Wichtowski M.: Wytrzymałość zmęczeniowa spoin czołowych z nakładkami wg Eurokodu 3. Przegląd Spawalnictwa 3/2011 s. 36.

[11] Werner K., Wojsyk K.: Analiza możliwości kruchego pękania spawanych elementów konstrukcji stalowych. Przegląd Spawalnictwa 5/2015 s. 91-93.

[12] Miśta J. Ocena dopuszczalności niezgodności spawalniczych dokonywana na postawie mechaniki pękania w złączach ze stali typu S355 w różnych temperaturach. Praca magisterska pod kier. K. Wojsyka, Częstochowa 2013 